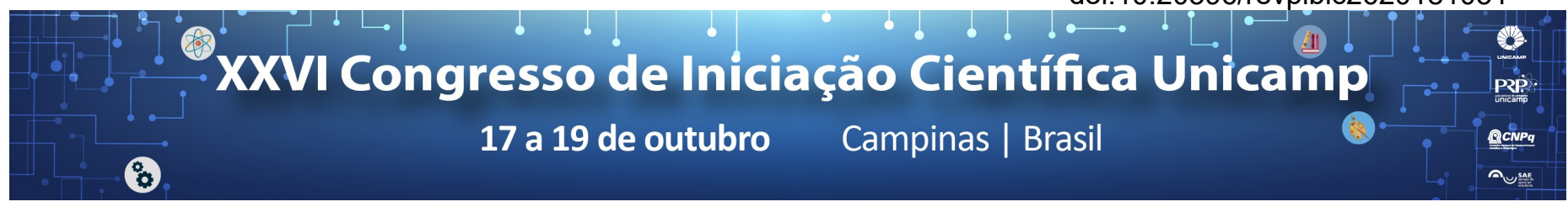

\title{
Aplicação de Internet das Coisas na Cadeia do Frio de Fármacos
}

\author{
Matheus de C. Quirino*, Natália M. Moreno, Orlando F. Lima Jr.
}

\section{Resumo}

Embora cresça a preocupação com as condições dos medicamentos na cadeia de suprimentos, os resultados alcançados permanecem incipientes e a disponibilidade de informações, escassa. Nesse cenário, a pesquisa analisou alternativas para produtos que requerem controle das condições de temperatura na distribuição. Assim, o estudo aborda a Cadeia do Frio de Fármacos (PCC) avaliando as características desse sistema e desenvolvendo um Modelo Baseado em Agentes (ABM) para o transporte dos medicamentos. Com a pesquisa, espera-se contribuir para que a PCC se consolide como uma rede efetiva na difusão de conhecimento entre seus atores.

\section{Palavras-chave:}

Cadeia do Frio dos Fármacos, Internet das Coisas, Simulação Baseada em Agentes.

\section{Introdução}

O setor farmacêutico compreende uma cadeia dinâmica e dotada de um alto nível de recursos, sendo movida pelo desenvolvimento de novos produtos e pelo crescimento no consumo (QUINTILESIMS INSTITUTE, 2016). No caso, constituída pela indústria e pelos agentes com quem ela interage, a Cadeia de Suprimento dos Fármacos (PSC) integra as etapas de suprimento, fabricação e distribuição para fornecer os medicamentos aos usuários nas condições esperadas (ENYINDA; MBAH; OGBUEHI, 2010). Contudo, em geral, esse propósito não é atingido no controle de qualidade, o que, diante da vulnerabilidade comum aos fármacos, torna-se um fator crítico.

Assim, são necessárias alternativas que aprimorem a roteirização na Cadeia do Frio dos Fármacos (PCC). Nessa direção, pode-se desenvolver modelos de simulação integrados à Internet das Coisas (IoT), entendida como uma rede de conexões em que objetos inteligentes são capazes de serem identificados e de se comunicarem. (MIORANDI et al., 2012).

Mais especificamente, o estudo pretende caracterizar a PCC e desenvolver um ABM que atenda aos problemas de inspeção de temperatura, de monitoramento de desempenho e de redução no tempo de transporte, proporcionando o controle em tempo real do produto.

\section{Resultados e Discussão}

Primeiramente, realizou-se uma revisão bibliográfica, identificando os principais tópicos relacionados à PCC e analisando os estudos já publicados sobre tais assuntos. Com base nesse trabalho, determinou-se quais são as restrições térmicas que cada tipo de fármaco apresenta.

Concluído esse estágio, modelou-se a cadeia. Para isso, escolheu-se a simulação baseada em agentes por ela proporcionar tanto rapidez e facilidade de modelagem quanto adequação aos problemas da pesquisa.

Previamente à elaboração computacional, realizou-se um modelo conceitual, em que se impuseram as situações críticas às estabilidades térmicas do produto e em que se gerou uma variável de controle para o acompanhamento dessas condições. Após isso, matrizes de distâncias e de tempo de viagens entre 10 pontos de distribuição em Campinas - SP foram geradas para que se pudesse determinar, continuamente, o percurso mais adequado à conservação da qualidade do produto.

Em posse dessas informações e de um conjunto de dados para diversas faixas de temperatura do produto, buscou-se consolidar o modelo computacional pelo seu desenvolvimento em um software voltado à métodos de simulação.

A partir desse estudo, observa-se que as flutuações térmicas exercem influência significativa ao decorrer da distribuição. Entretanto, nota-se que, com base no ABM, é possível contornar tais variações dentro dos limites estipulados como aceitáveis, ajustando a rota em tempo real e, com isso, aumentando a garantia da qualidade dos medicamentos.

\section{Conclusões}

Em prol do controle dos fármacos e da difusão de informações entre os agentes de uma cadeia complexa como a PCC, o estudo integrou os desafios desse sistema aos avanços nas Tecnologias de Informação e Comunicação. A partir dos resultados, nota-se que o $\mathrm{ABM}$ é uma alternativa interessante para o acompanhamento em tempo real dos produtos ao longo do processo de distribuição.

\section{Agradecimentos}

Agradeço ao Conselho Nacional de Desenvolvimento Científico e Tecnológico (CNPq) pelo fomento à pesquisa. Agradeço, também, à equipe do Laboratório de Aprendizagem em Logística e Transporte (LALT) pelo apoio e pelo contínuo suporte ao longo do estudo.

QUINTILESIMS INSTITUTE. Outlook for Global Medicines through 2021: Balancing Cost and Value. n. December, p. 55, 2016.

LAW, Averill M. Simulation Modeling and Analysis. 5. ed. New York: McGraw-Hill Education, 2015.

MIORANDI, D. et al. Internet of things: Vision, applications and research challenges. Ad Hoc Networks, v. 10, n. 7, p. 1497-1516, 2012.

ENYINDA, C. I.; MBAH, C. H. N.; OGBUEHI, A. An empirical analysis of risk mitigation in the pharmaceutical industry supply chain: A developingcountry perspective. Thunderbird International Business Review, v. 52, n. 1, p. 45-54, 2010. 